\title{
Analysis of the composition of alternative energy sources in the regional energy system
}

\author{
Angela Yusupova ${ }^{1, *}$, Baysangur Yusupov ${ }^{1}$, Mayrbek Debiyev ${ }^{1}$, Suliman Masaev ${ }^{1}$, Timur Amkhaev ${ }^{1}$, and Anu Madaeva ${ }^{1}$ \\ ${ }^{1}$ Grozny State Oil Technical University, Grozny, Russia
}

\begin{abstract}
The regional authorities, solving energy issues via the development of small-scale energy capacities, enable more adaptive and economical solution of the problems of energy development at the regional level. Thus, one of the foundations of small-scale energy is the use of alternative energy sources. Formation of schemes and procedures for the development of regional energy modalities based on the active use of alternative energy sources is the objective of developing the energy industry, both at the regional level and throughout the country. In order to solve this problem, an analysis of all available alternative energy sources in the regional energy system is carried out. Although the discussion on this issue is extensive, special attention is paid to the analysis of the problems associated with the introduction and development of alternative energy systems. This article describes procedures for generating a set of global factors that can have a significant impact on the implementation or operation of alternative energy systems. Based on the systematic approach and the resulting composition of global factors, a composition of eighteen influencing factors was identified. The presence of a systemically complete set of indicators describing the factors of influence on the process of functioning of alternative energy systems in the region makes it possible to set and formalize a number of important ones. The descriptions of three interesting issues for the implementation and development of alternative energy systems are given in this paper. For future developments, we plan to list models of the issues, as well as to develop practices to overcome these issues.
\end{abstract}

\section{Introduction}

Currently, most of the developed countries of the world consider the development of small-scale power engineering as one of the important directions of development of the energy sector. This is due, in particular, to the fact that small-scale energy is perspective for implementation at the regional level without attracting large centralized funds. In addition, small-scale energy is often more environmentally friendly than large-scale energy. Finally, the regional authorities, solving energy problems through the development of small-scale power generation capacities, make it possible to more adaptively and economically solve the problems of energy development at the regional level. It should be pointed out that small-scale energy is a segment of the energy economy, which includes small generating plants and small generating complexes, including those not connected to centralized power grids, operating on the basis of traditional fuels and on the basis of renewable energy sources [15].

The modern attitude to alternative energy - in contrast to past years, when renewable and alternative energy was considered as great assistance in solving many pressing issues in the energy sector, in the environment, in the field of security - has become more balanced and rational. Namely, a number of serious shortcomings associated with alternative energy have emerged, which are not so acute in the case of traditionally energy based on fossil energy sources. The main disadvantages are discussed below. Here are some of the economic aspects of this issue.

Lately, huge funds have been invested in the development of alternative energy - from 2011 to 2018, about $55 \%$ of the 3.66 trillion dollars (that is, more than 2 trillion), which were spent on combating climate change; in particular on the development of solar and wind energy in order to reduce greenhouse gas emissions and other impacts on the environment from fossil fuels. During this period, the capacity of solar energy increased by $33 \%$, wind power by $22 \%$, other types of renewable energy by $10 \%$, that is, in general, a significant increase in alternative energy sources capacities. For comparison, we present data on the percentage of various types of energy at the end of 2018: thermal power plants using oil $34 \%$, coal-fired $27 \%$, gas-fired $24 \%$, hydropower plants $7 \%$, nuclear power plants $4 \%$, wind power plants $2 \%$, solar power plants $1 \%$, other $1 \%$.

It should be noted that there are many papers on the alternative energy sources; in particular [1], [2], [3], [10], [13]. There are relatively few papers on the given topic; specifically these [4], [5].

Thus, one of the foundations of small-scale energy is the use of alternative energy sources. Therefore, the formation of schemes and procedures for the development of regional energy modalities based on the

\footnotetext{
* Corresponding author: yusupova-as@mail.ru
} 
active use of alternative energy sources is the objective of developing the energy industry both at the regional level and throughout the country. This objective will be discussed in this paper.

\section{Classification of existing alternative energy sources}

In order to solve this problem, first of all we will analyse all available alternative energy sources at the regional level.

Based on the analysis of literary sources, it is possible to briefly list the following types of the main alternative energy sources that may be of interest at the regional level. More meaningfully with these types of alternative energy sources can be found in [1], [2], [3], [6], [12], [14]. Note that currently, research is underway on other types of alternative energy sources; in particular, cryogenic energy, thunderstorm, gravitational, etc.

1. Solar energy. Includes solar energy (used in more than 80 countries); also power towers, photovoltaic cells, nanoantennas.

2. Wind power. The use of wind power plants is developing intensively, especially in Europe: Denmark (48\% of electricity is from wind, Ireland (33\%), Portugal (27\%), Germany (26\%), Great Britain (22\%). Also, wind energy is intensively developing in China, USA, India.

3. Biomass energy operated on biofuels: liquid (biodiesel, bioethanol), solid (primarily all wood, fuel briquettes), gaseous (biogas, synthesis gas).

4. Wave energy. It relies on obtaining electrical energy by converting the energy of underwater currents and waves.

5. Gradient temperature energy. Relies on energy production based on temperature differences. Most of the gradient-temperature power plants are located on the sea coast and use sea water for operation, more precisely, the temperature differences between cold waters at a depth of several hundred meters and warm waters at the surface.

6. Tidal energy. It uses the energy of the tides.

7. Geothermal energy. It relies on generating electricity by converting the Earth's internal heat (energy from hot steam-water sources) into electrical energy.

8. Energy based on the shape memory effect. This effect is observed in special alloys and refers to parts being restored to the initial shape after deformation under thermal action. In this case, the useful output of restoring the original form is performed. For now, there is low efficiency - only 5-6 percent.

Naturally, in specific regions, not all of the listed sources may be available, and, if available, may be of interest from the point of view of their potential effectiveness. Therefore, the choice of the composition of possible types of alternative energy sources in each specific case, as applied to each specific region, should be individual and adaptive. For a scientifically grounded choice of the alternative energy sources composition in a specific region, it is first necessary to form a composition of indicators by which the comparison of various alternative energy sources is carried out.

\section{Formation of the composition of the criteria for comparing various alternative energy sources}

Earlier in his paper [6] one of the authors dealt with this issue. However, in this paper, when forming the list of indicators by which the significance of the considered alternative energy sources was assessed, they did not take into account, firstly, the entire list of possible alternative energy sources given above, and secondly, the regional aspects of this task were not taken into account. In addition, a number of studies in recent years have revealed a number of negative consequences of the development of alternative energy, which significantly reduced its value as an alternative to traditional energy [7], [8]. In this regard, a number of countries have begun to partially scale back their large-scale programs for the development of alternative energy as opposed to traditional, based on fossil energy sources. Therefore, the question naturally arises of identifying the most optimal combination of traditional and alternative energy.

Alternative energy undoubtedly has a number of important environmental benefits. Almost all of its types (with the exception, perhaps, biofuel) do not have any harmful emissions, process waste, do not require the laying of power grids. More precisely, if necessary, alternative energy sources can be connected to existing networks or combined into networks. But they can also work autonomously. It is these advantages that were one of the driving motives for the large-scale development of alternative energy in a number of countries - Germany, China, etc [11].

However, alternative energy has a number of disadvantages. Below is the list some of the most important identified disadvantages of alternative energy [8].

1. Impact on the environment. In some cases, for example, wind farms and solar panels increase the temperature of the soil below them, which leads to the activation of soil microbes and soil plants. On the one hand, this leads to an increase in the emission of carbon dioxide - negative effect, which can be significant with a large scale use of wind and solar energy, and on the other hand, it can be successfully used in highmountainous and other areas with low seasonal temperatures, as well as in certain economic areas, for example, in pasture animal husbandry. Thus, this factor associated with the use of alternative energy sources has both positive and negative aspects, and in each case, it is necessary to assess its complex significance, taking into account all the positive and negative aspects.

2. The development of many areas of alternative energy sources leads to significant indirect costs associated with the extraction of mineral resources in comparison with electricity generated by burning fossil fuels; in particular cobalt, neodymium and lithium, as well as copper. 
3. Solar and wind parks require tens and hundreds of times more land surface than electricity from fossil fuels. Moreover, emerging changes in land use patterns can have a devastating impact on biodiversity. The impact of bioenergy on biodiversity is even worse.

Consequently, the first group of criteria is designed to assess and take into account all positive and negative environmental aspects of the development of alternative energy.

One of the main goals of the development of alternative energy is associated with ensuring the most acceptable energy conditions to meet the needs of the population in the energy sector, as well as for the development of certain sectors of the economy that can effectively take advantage of all the advantages of alternative energy and are significant for the regional economy. That is, it is necessary to determine those economic areas in which it is advisable to use various types of alternative energy, the volume of its use, associated costs and expenses, implementation mechanisms, etc. However, when using alternative energy sources, certain difficulties also arise on these issues. We list some of them.

1) Relatively low efficiency. 2011 to 2018 the development of wind and solar energy was spent an amount of about two trillion dollars. Ultimately, these energy sectors produce only $3 \%$ of world consumption (in $2011-0.5 \%$ ). While fossil energy sources without such significant costs produce $85 \%$ of energy consumption. The question arises about the profitability of the development of alternative energy. Further, for 8 years with large-scale investments, the growth is only $2.5 \%$. Then bringing the share of alternative energy to several tens of percent, as planned by some countries, will require enormous costs and take long time, which raises the question of the feasibility of large-scale development of alternative energy.

2) Technological impediments. Wind and solar parks have a significant technological drawback: they generate energy periodically, more precisely, only if there are appropriate wind conditions or lighting conditions, which is not always the case. The problem could be solved by using large-scale accumulator energy storage devices. However, modern technologies are such that the implementation of such systems will require huge land areas - about 1 hectare (completely filled with technical devices) for $130 \mathrm{MW} * \mathrm{~h}$ of energy produced (taking into account the peak load). Then the average Russian region will require many tens and even hundreds of hectares of such hectares clogged with technical equipment.

3) Social aspects. Studies in a number of European countries and in China [9] have shown that fossil energy sources are the most affordable and cheapest energy sources in many countries, especially for the poorest households and in rural areas. The large-scale introduction of alternative energy will lead to the fact that the main burden on the development of alternative energy systems will fall on these poorest segments of society, which violates the principles of social justice. In addition, the creation of large-scale storage batteries requires huge amounts of cobalt and lithium, which in many cases will lead to disruption of the usual way of life of the ordinary population adjacent to the places of their extraction, especially taking into account the environmental hazard of these extractive industries.

However, there are a number of important advantages of alternative energy that make it attractive precisely for solving problems of energy supply to the region. First of all, it is adaptive. Alternative energy sources can be located in the most unfavourable conditions, far from developed territories, in high mountains (for example, on pastures or tourist camps), in deserts, in harmful climatic and other conditions. Further, alternative energy sources requires costs comparable to the capabilities of the regional budget, individual organizations, entrepreneurs, and individual households. Finally, alternative energy sources in many cases can be mobile transferred, if necessary, from one place to another.

From all of the above, we conclude that the second group of criteria should be aimed at identifying the needs of the region in alternative energy, based on its economic opportunities, including economic, technological and social aspects.

When solving the problem of developing regional energy (RE), including alternative energy, it is also necessary to rely on the plans of the federal government in the field of energy, the possibility of participating in these plans, adjusting them taking into account the interests of the region in order to attract financial resources from the federal budget for the development of alternative energy, active participation in solving regional energy problems, in providing more favourable conditions for the development of the regional economy. One of the forms of participation is also the receipt of grants and subsidies from various sources, including non-governmental ones. Therefore, the third group of criteria describes the degree of interconnection and complementarity of regional and federal programs for the development of alternative energy.

The next most important group of criteria are the criteria associated with assessing the degree of efficiency of the selected composition of alternative energy sources, investment options and their development, which allows you to choose the most appropriate option. These criteria shall, first of all take into account the technological and economic capabilities of the region when solving this problem, as well as social and economic aspects related to the degree of satisfaction of the population and economic entities with services in the energy sector. The foregoing emphasizes the complex nature of the indicators of the fourth group, covering many aspects of the development of alternative energy sources.

Finally, in view of fairly wide variety of options for the development of energy potential when using alternative energy sources, it is necessary to take into account the main trends in the development of energy and alternative energy sources, the prospects of various options for the development of alternative energy sources, the possibilities of their modernization and development. All these aspects of alternative energy sources development shall be taken into account in the indicators of this group. The significance of this 
indicator is also determined by the fact that alternative energy at the regional level is subject to greater uncertainty associated, in particular, with possible changes in energy policy at the federal level, and therefore should have greater adaptability to possible changes in the system.

It is proposed to use an interval of 20 years as the time duration for the relevance of the criteria, which is necessary for substantive content of the criteria and its numerical assessment. This time period is often used in long-term planning tasks.

The above descriptions of influencing factors on the effectiveness of the introduction and functioning of the alternative energy at the regional level are shown in Fig. 1 as a diagram of influencing factors. Some clarifying explanations on the diagram in Fig. 1.

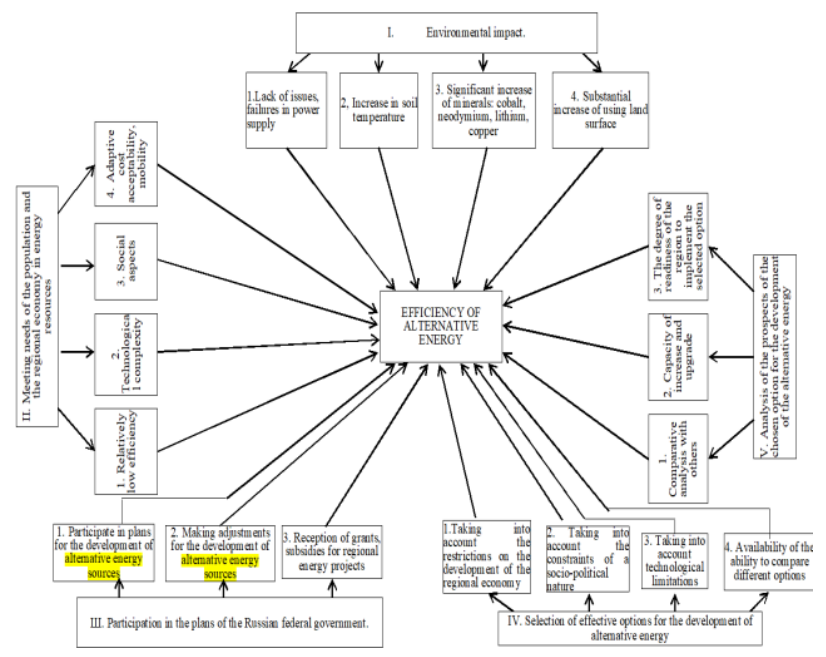

Fig. 1. Influence factors classification diagrams on the efficiency of implementation and functioning of alternative energy in the region.

The central element of the diagram is the rectangle in its centre, which is the formulation of the main goal of the development of alternative energy - ensuring the maximum efficiency of its functioning from the point of view of the interests of the region. The concept of efficiency requires clarification and disclosure of the content, it has a complex character, covering both economic aspects and socio-political, technological and regional aspects. For different regions, the content of the concept of efficiency may be different.

Directly the content and state of the efficiency of alternative energy is determined by five global factors influencing efficiency, described above and numbered in the diagram in Latin numbering.

Each of the global factors of influence breaks down into a number of simpler factors, most of which were discussed above. However, some of the factors above were not discussed in detail, and therefore we will clarify their content. This concerns, first of all, global factors IV "Selection of effective options for the development of alternative energy" and V "Analysis of the prospects of the selected option for the development of alternative energy". Now take a closer look at these influencing factors. Starting with the most important from the point of view of developing technology for implementing a project for the development of alternative energy in the region - from global factor IV, associated with finding the most acceptable and effective ways to develop alternative energy in the region.

With regard to global factor IV, the following influencing factors are identified.

1) Taking into account the restrictions on the development of the regional economy. The development of alternative energy in the region directly depends on the financial and economic state of the regional economy, since the main share of funding for projects related to the development of alternative energy at the regional level comes from regional funds. In this case, not only the general state of the region's economy is important, but also the dynamics of its development, since the dynamics of the development of alternative energy can be synchronized with changes in the financial and economic capabilities of the region (for example, after the completion of a major project in the region).

2) Taking into account social and political constraints. The issues of social support and development of certain districts and settlements of the region, as well as certain areas of activity, may require the creation of energy capacities in these territories, despite the presence of more economically promising development options. The need to make adjustments and changes to plans for the development of alternative energy may also be due to political reasons: for example, in order to maintain certain more preferred regions.

3) Taking into account technological limitations and capabilities of the region. The development of regional energy is often connected and more efficient in the presence of a specific road transport system. In addition, the creation, operation and development of alternative energy is much more efficient in the presence of a certain qualified human potential and appropriate production capabilities.

4) The availability of opportunities for the development and comparison of various options for the development of alternative energy in the region. This factor is one of the most important after factor 1). It presupposes the presence of a certain scientific and engineering-technical potential, capable of either participating in exploratory research, in relevant technological developments, or capable of adequately assessing the quality of developments performed by third-party performers. If there is no such potential in the region, then it is possible to attract outside experts. However, it is often necessary to adjust the developed projects even after their completion. Therefore, it is advisable to have your own scientific and technical potential in the region, and in its absence, create it.

Now consider the global factor $\mathrm{V}$ "Analysis of the prospects of the selected alternative energy development option".

1) Comparative analysis with other countries and with other regions. This factor assumes the fullest possible use of experience in this area in other countries, as well as in other regions of the country, if such experience exists. Analysis of the experience already accumulated in this or a related area, its adaptation to the conditions of the region with full consideration of all its 
features and its specifics. This factor may be decisive in the process of choosing options for the development of alternative energy.

2) Possibilities for building up and modernizing the alternative energy system in the region. In the field of alternative energy, there is currently rapid development in all areas: the search and development of new technologies and sources of renewable and alternative energy, more advanced technical solutions and devices, control systems that increase the efficiency of systems operation, their functioning, and profitability. Therefore, the analysis of possible changes in the selected option and rapid modernization of the system is very important from the point of view of the prospects for its long-term use.

3) The degree of the region's readiness to implement the selected option. This factor presupposes the elimination of those elements of the chosen option for the development of alternative energy that are less acceptable for the region for a variety of reasons, ranging from natural and climatic and socio-political and ending with purely subjective, associated with the positions of responsible and authorized persons and leaders.

Thus, five global factors have been identified that determine the effectiveness of the introduction and operation of alternative energy at the regional level. On their basis, a composition of eighteen factors of influence on the process of functioning and improvement of alternative energy in the region was formed. The next stage in the implementation of the task is the formation of a list of measurable indicators for each factor. Next, it is necessary to develop and describe methods for assessing the values of these indicators. Then, to form procedures for a comprehensive and integral assessment of the chosen option for the development of alternative energy and alternative options in order to create a procedure for comparing all possible options for the development of alternative energy on the basis of a single methodology.

The presence of a systemically complete set of indicators describing the factors of influence on the process of functioning of alternative energy systems in the region makes it possible to put and formalize a number of important ones. The following three tasks listed below with the description.

Objective of an optimal resource allocation. There is a certain amount of financial resources allocated for the development of alternative energy in the region for a given regulatory time period.

For each type of alternative energy sources, there are a number of options for its placement in the region; for each placement, the following are known: its energy capacity at different periods of time during a regulatory period of time and for a given amount of investment; acquisition, installation and operating costs; risks and losses associated with operation; the expected demand for the generated energy. Find such a composition and allocated funds for each placement point, at which the total reduced profit (that is, minus all losses, costs and risks) would be the greatest, and the total costs did not exceed a given value. The considered objective is one of the main tasks being solved in the process of developing alternative energy systems in the region.

Assess the most acceptable scale of development of alternative energy in the region, at which the total costs, losses and costs are minimal. Recall that, as indicated above, the large-scale development of alternative energy is practically impossible due to massive environmental, technological, and financial costs. Therefore, there is an optimal average level of development, which must be determined.

For the chosen alternative energy development option, determine the optimal sequence and stages of implementation of alternative energy systems. That is, what and where to create and implement in the first place, what in the second (and when to implement the second), what in the third, etc.

The formalization of the list of tasks, as well as the development of methods for their solution is supposed to be carried out in the subsequent works of the authors.

\section{Conclusion}

This paper analyses the problems associated with the introduction and development of alternative energy systems. The sequence for the formation of a set of global factors that can have a significant impact on the implementation or operation of alternative energy systems is described. On the basis of systematic approach and the obtained composition of global factors, composition of eighteen influencing factors was identified. Descriptions of three tasks of interest in the implementation and development of alternative energy systems are given.

\section{References}

1. M.E. Rodionova, P.S. Seleznev, I.V. Yushkov, S.P. Mitrakhovich, Energy in the Modern World (Knorus, 423, 2019)

2. F.I. Sukhov, Alternative energy sources, Textbook (KnoRus, 345, 2020)

3. T.K. Ivanova, V.M. Ivanov, V.Y. Fedyanin, I.A. Bakhtina, S.O. Khomutov, Fundamentals of the use of non-traditional and renewable energy sources (Barnaul: LLC "Interregional center for electronic educational resources", 148, 2018) ISBN: 978-5-6040354-2-9

4. I.A. Kerimov, M.V. Debiev, Priority directions of energy development in the Chechen Republic, Methodological issues of researching the reliability of large energy systems, 92nd meeting of the seminar established at ISEM SB RAS (In 3 books, Irkutsk, 19-28, 2020)

5. M.V. Debiev, S.Kh. Masaev, A.S. Yusupova, B.S. Yusupov, Features of the selection and placement of wind power plants, Grozny natural science bulletin, 4-3 (17), 91-100 (2019)

6. O.L. Tashlykov, S.E. Shcheklein, Y.E. Nemikhin, Power plants based on non-traditional and renewable energy sources, Methodical 
recommendations for diploma design (Flinta, 59, 2018)

7. Electronic resource Available at: https://www.mdpi.com/1996-1073/13/18/4839

8. Óh. Aiseadha, C. Quinn, G. Connolly, R. Connolly, M. Soon, Energy and Climate Policy, An Evaluation of Global Climate Change Expenditure 2011-2018, Energies, 13, 4839 (2020)

9. B.S. Yusupov, A.S. Yusupova, M.V. Debiev, R.A.M. Magomadov, Possibility of using alternative energy sources in Chechen Republic, Contemporary Issues of Geology, Geophysics and Geoecology of the North Caucasus, CIGGG 2018, 316-318 (2018)

10. M.V. Debiev, A.S. Yusupova, Development of the electric power industry in Russia, Proceedings of the Grozny State Oil Technical University named after Academician M.D. Millionshchikova, 16-17, 124-130 (2018)

11. I.A. Kerimov, M.V. Debiev, Green energy as a factor of sustainable development of the Chechen Republic, Sustainable development of mountainous areas, 10-2 (36), 235-245 (2018)

12. M.V. Debiev, Kh.I. Khamsurkaev, T.Sh. Amkhaev, Renewable energy of the Chechen Republic, Interregional center for electronic educational resources, Materials of the I International scientific-practical conference dedicated to the 100th anniversary of FSBEI HE "GGNTU named after academician MD Millionshchikov": in 2 volumes, Grozny State Oil Technical University named after academician M.D. Millionshchikova, 231-234 (2017)

13. M.V. Debiev, Analysis of the effectiveness of the development of the regional energy industry (on the example of the Chechen Republic)

abstract dis. ... candidate of technical sciences, Volgogr. state tech. un-t., Volgograd (2014)

14. M.V. Debiev, Kh.I. Khamsurkaev, T.Sh. Amkhaev, Renewable energy of the Chechen Republic, Interregional center for electronic educational resources, Materials of the I International scientific-practical conference dedicated to the 100th anniversary of FSBEI HE "GGNTU named after academician MD Millionshchikov": in 2 volumes, Grozny State Oil Technical University named after academician M.D. Millionshchikova, 231-234 (2017)

15. Energetika [Electronic resource] Available at: https://www.np-sr.ru/ru/glossary/item/malaya. 